\title{
The value of urinary uric acid and creatinine ratio in neonatal asphyxia
}

\author{
Gupta N. ${ }^{1}$, Bhambri A. ${ }^{2}$, A Bhat V. ${ }^{3}$, Katyal R. ${ }^{4}$, Saxena S. ${ }^{5}$, Mishra S. ${ }^{6 *}$ \\ DOI: https://doi.org/10.17511/ijpr.2020.i08.06
}

\footnotetext{
1 Nikhil Gupta, Junior Resident, Department of Pediatrics, Rohilkhand Medical College and Hospital, Bareilly, Uttar Pradesh, India.

2 Alka Bhambri, Professor and Head of Department, Department of Pediatrics, Rohilkhand Medical College and Hospital, Bareilly, Uttar Pradesh, India.

3 Vedika A Bhat, Assistant Professor, Department of Pediatrics, Rohilkhand Medical College and Hospital, Bareilly, Uttar Pradesh, India.

4 Rashmi Katyal, Associate Professor, Department of Community Medicine, Rohilkhand Medical College and Hospital, Bareilly, Uttar Pradesh, India.

5 Shikha Saxena, Assistant Professor, Department of Biochemistry, Rohilkhand Medical College and Hospital, Bareilly, Uttar Pradesh, India.

6* Shashank Mishra, Assistant Professor, Department of Pediatrics, Rohilkhand Medical College and Hospital, Bareilly, Uttar Pradesh, India.
}

Objective: The value of urinary uric acid and creatinine ratio in neonatal asphyxia. Method: This was a prospective observational study conducted over one year, on 45 newborns admitted in NICU with perinatal asphyxia. Cord blood from the umbilical artery was sent for $\mathrm{pH}$ analysis and urinary uric acid and creatinine levels were estimated in spot urine samples. Results: The urinary uric acid and creatinine ratio had a positive correlation with low APGAR scores at the $1^{\text {st }}$ and $5^{\text {th }}$ minute. Also, urinary uric acid to creatinine ratios was significantly higher in infants with severe HIE (3.18 \pm 0.61$)$ when compared with infants of moderate HIE (2.19 \pm 0.32$)$. It showed a significant negative correlation with $\mathrm{pH}$ of cord blood in neonates with perinatal asphyxia. Conclusion: The urinary uric acid and creatinine ratio can be used as a supportive diagnostic test for early diagnosis of perinatal asphyxia.

Keywords: Uric acid, Creatinine, Neonatal asphyxia, Urinary uric acid

\section{Corresponding Author}

Shashank Mishra, Assistant Professor, Department of Pediatrics, Rohilkhand Medical College and Hospital, Bareilly, Uttar Pradesh, India.

Email: nikhil.gupta211092@gmail.com

\section{How to Cite this Article}

Gupta N, Bhambri A, Bhat VA, Katyal R, Saxena S, Mishra $S$. The value of urinary uric acid and creatinine ratio in neonatal asphyxia. Pediatric Rev Int J Pediatr Res. 2020;7(8):425-429.

Available From

https://pediatrics.medresearch.in/index.php/ijpr/arti cle/view/641
To Browse

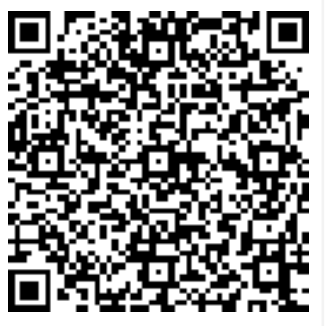

Manuscript Received 2020-12-09

Conflict of Interest No
Review Round 1 2020-12-19

Funding

Nil

$\begin{gathered}\text { Review Round } 2 \\ 2020-12-25\end{gathered}$
Ethical Approval
Yes

Review Round 2

Yes
Review Round 3

Plagiarism X-checker $9 \%$
Accepted 2020-12-28

Note

(C) 2020 by Nikhil Gupta, Alka Bhambri, Vedika A Bhat, Rashmi Katyal, Shikha Saxena, Shashank Mishra and Published by Siddharth Health Research and Social Welfare Society. This is an Open Access article licensed under a Creative Commons Attribution 4.0 International License https://creativecommons.org/licenses/by/4.0/ unported [CC BY 4.0]. 


\section{Introduction}

According to the latest estimates by the World Health Organization (WHO), approximately 4 million neonates die each year. Out of which perinatal asphyxia and birth injuries together contribute to almost $29 \%$ of these deaths [1]. As per the National Neonatal Perinatal Database (NNPD), data collected from 17 tertiary neonatal intensive care units in India, perinatal asphyxia was responsible for $20 \%$ of all neonatal deaths. The manifestation of hypoxicischemic encephalopathy (HIE) was seen in approximately $1.5 \%$ of all babies.

Perinatal asphyxia was the commonest cause of stillbirths, accounting for one-third of all such cases. In addition to this, antepartum and intrapartum asphyxia contributes to 300,000 to 400,000 stillbirths. In India, $8.4 \%$ of inborn babies have 1 minute APGAR scoreless than 7 and $1.4 \%$ suffer hypoxic-ischemic encephalopathy. Though there are many studies, data on early determination of the tissue damages due to birth asphyxia are still lacking [2].

The APGAR score is most commonly used as the diagnostic and prognostic indicator of birth asphyxia, the 1-minute APGAR score reflects the need for immediate resuscitation. The change in score between 1 and 5 minutes is a useful index for the effectiveness of resuscitative efforts [2]. A hypoxic-ischemic insult, but also many other nonasphyxia factors such as maternal analgesia, fetal malformations, prematurity, and infection, may cause depression of the APGAR score. A prolonged depression of the APGAR score is related to death or severe neurodevelopment outcome [3].

Whereas APGAR score and umbilical artery blood $\mathrm{pH}$ both predict neonatal mortality in term and preterm infants, indicators such as $\mathrm{pH}$, lactates, and base deficits subside with the establishment of respiration, these techniques are however costly and sophisticated. Also, $\mathrm{pH}$, lactate, and base deficit estimations are invasive and require sophisticated instruments. But the ratio of urinary uric acid to creatinine ratio is a simple, cost-effective, noninvasive, and early biochemical means of asphyxia diagnosis [4].

Urinary creatinine can be used as the reference substrate in a spot urine sample. An increased $\mathrm{UA} / \mathrm{Cr}$ ratio (as a sign of increased ATP degradation) may be a valuable indicator of the severity of tissue hypoxia in patients with intact renal functions.
A recent study has revealed a significant increase in $\mathrm{UA} / \mathrm{Cr}$ ratio in early spot urine samples from asphyxiated full-term newborns. The study also proved a positive correlation between the urinary $\mathrm{UA} / \mathrm{Cr}$ ratio and the severity (grading) of $\mathrm{HIE}(\mathrm{P}<$ $0.001)$ [5].

\section{Materials and Methods}

The study was conducted in the NICU of the Department of Paediatrics, Rohilkhand Medical College and Hospital, Bareilly, which is a tertiary center.

This prospective observational study was conducted over one year, from November 2018 to October 2019 on 45 newborns, after taking ethical clearance from the institutional ethical committee. All newborns admitted in NICU or nursery in the department of pediatrics with a history of intrapartum fetal distress with or without the presence of meconium staining of amniotic fluid or APGAR score $<7$ at 1 minute of birth or requiring immediate neonatal resuscitation with ventilation by bag and mask or via an endotracheal tube for more than one minute were included in the study. Neonates with major congenital malformations, suspected of congenital infections, anuria, born to mothers having hypertension or diabetes mellitus or having toxemia of pregnancy, mothers receiving general anesthesia or refusal to be included in the study by parents/caregiver were excluded from the study.

A detailed history and neurological examination were done for all neonates included in the study. Asphyxiated neonates were monitored for seizures, hypotonia, and hypoxic-ischemic encephalopathy in the immediate neonatal period in NICU. The severity of hypoxic-ischemic encephalopathy was graded using SARNAT and SARNAT staging. Cord blood from the umbilical artery was sent for $\mathrm{pH}$ analysis. The spot urine samples were collected within 6-24 hours of life. The urinary uric acid level was measured using autoanalyzer by spectrophotometric uricase method whereas urinary creatinine level was estimated using Jaffe's alkaline picrate method. Data analyzed using SPSS (Statistical Package for the Social Science) Version 22.

\section{Results}

A total of 45 patients were enrolled in the present study. Baseline characteristics of the study population are given in Table-1. 
Table-1: Baseline characteristics.

\begin{tabular}{|c|c|c|}
\hline Parameters & & Percentage \\
\hline \multirow[t]{2}{*}{ Gender } & Male & 31.1 \\
\hline & Female & 68.9 \\
\hline \multirow[t]{2}{*}{ Birth weight (kg) } & $<2.5$ & 64.4 \\
\hline & $>2.5$ & 35.6 \\
\hline \multirow[t]{3}{*}{ Ballard scoring } & Preterm & 66.7 \\
\hline & Term & 31.1 \\
\hline & Post-term & 2.3 \\
\hline \multirow[t]{4}{*}{ HIE Grade } & NO HIE & 35.6 \\
\hline & Grade I & 28.9 \\
\hline & Grade II & 24.4 \\
\hline & Grade III & 11 \\
\hline \multirow[t]{3}{*}{ Apgar Score at $1 \mathrm{~min}$} & $0-3$ & 0 \\
\hline & $4-6$ & 85.9 \\
\hline & $>7$ & 11.1 \\
\hline \multirow[t]{3}{*}{ Apgar Score at $5 \mathrm{~min}$} & $0-3$ & 0 \\
\hline & $4-6$ & 24.4 \\
\hline & $>7$ & 75.6 \\
\hline \multirow[t]{2}{*}{ Neonates with seizures } & Yes & 11.11 \\
\hline & No & 88.88 \\
\hline \multirow[t]{3}{*}{ Tone } & Normal & 64.45 \\
\hline & Hypertonia & 0 \\
\hline & Hypotonia & 35.5 \\
\hline
\end{tabular}

A total of 40 neonates had a low APGAR score at the end of 1 st minute in the range of (4-6). Out of which, 23(57.5\%) neonates had urinary uric acid and creatinine ratio $>1.96$, and $17(42.5 \%)$ neonates had urinary uric acid and creatinine ratio in the range of $0.42-1.96$.

Rest 5 newborns who had an APGAR score of $\geq 7$ had urinary uric acid and creatinine ratio in the range of $0.42-1.96$. Thus, there was a significant correlation of urinary uric acid to creatinine ratio and low APGAR score at 1st minute ( $p$ value $=$ 0.015).

In the present study, 11 neonates (24.4\%) had a Iow APGAR score (4-6) at the end of 5 minutes. Out of these, $9(81.8 \%)$ neonates had urinary uric acid and creatinine ratio in the range $>1.96$, and $2(18.2 \%)$ neonates had normal urinary uric acid and creatinine ratio in the range of $(0.42-1.96)$.

Out of the $34(77.6 \%)$, neonates who had an APGAR score $\geq$ of 7 (at the end of 5 minutes), 20(58.8\%) neonates had urinary uric acid and creatinine ratio of (0.42-1.96) and $14(41.2 \%)$ neonates had urinary uric acid and creatinine ratio $>1.96$. It was observed that there was a significant correlation of urinary uric acid to creatinine ratio and Iow APGAR score at 5 minutes.
Table-2: Correlation of HIE Stage with $U$. Uric Acid / U. Creatinine Ratio.

\begin{tabular}{|l|l|l|l|l|}
\hline \multicolumn{5}{|c|}{ U. Uric acid / U. creatinine Ratio } \\
\cline { 1 - 4 } HIE Stage & $0.42-1.96$ & $>1.96$ & Total & P-VALUE \\
\hline No HIE & $15(93.8 \%)$ & $1(6.3 \%)$ & $16(35.6 \%)$ & \\
\cline { 1 - 4 } HIE Stage1 & $7(53.8 \%)$ & $6(46.2 \%)$ & $13(28.9 \%)$ & \multirow{2}{*}{0.001} \\
\cline { 1 - 4 } HIE Stage 2 & $0(0 \%)$ & $11(100 \%)$ & $11(29.4 \%)$ & \\
\cline { 1 - 4 } HIE Stage 3 & $0(0 \%)$ & $5(100 \%)$ & $5(11.1 \%)$ & \\
\cline { 1 - 4 } Total & $22(48.9 \%)$ & $23(51.1 \%)$ & $45(100 \%)$ & \\
\hline
\end{tabular}

In the present study, a higher urinary uric acid to creatinine ratio $(>1.96$ ) was found in $51.1 \%$ of asphyxiated neonates. Urinary uric acid to creatinine ratios was significantly higher in neonates with severe HIE (3.18 \pm 0.61$)$ when compared to neonates with moderate HIE $(2.19 \pm 0.32$ : $p<0.001)$. Hence there was a positive correlation between the urinary uric acid to creatinine ratio and the severity (grading) of HIE $(p<0.001)$.

Table-3: Correlation of pH of Cord Blood Level with Uric Acid / Creatinine Ratio.

\begin{tabular}{|l|l|l|l|l|}
\hline \multicolumn{5}{|c|}{ U. Uric acid/U. Creatinine Ratio } \\
\cline { 1 - 4 } pH of cord blood & $0.42-1.96$ & $>1.96$ & Total & P-VALUE \\
\hline $7.14-7.4$ & $22(78.6 \%)$ & $6(21.4 \%)$ & $28(62.2 \%)$ & \multirow{2}{*}{0.001} \\
\cline { 1 - 4 }$<7.14$ & $0(0 \%)$ & $79(100 \%)$ & $17(37.8 \%)$ & \\
\cline { 1 - 4 } Total & $22(48.9 \%)$ & $23(51.1 \%)$ & $45(100 \%)$ & \\
\hline
\end{tabular}

In this index study of 45 neonates, the $\mathrm{pH}$ of all neonates had been evaluated from cord blood. About $28(62.6 \%)$ neonates had $\mathrm{pH}$ in the range of 7.14-7.4. Amongst these 28 neonates, 22(78.6\%) neonates had urinary uric acid to creatinine ratio in the range of $0.42-1.96$, and $6(21.4 \%)$ neonates had a ratio $>1.96$. The rest 17 neonates with $\mathrm{pH}<7.14$ had urinary uric acid to creatinine ratio $>1.96$. There was a significant correlation of $\mathrm{pH}$ cord blood levels with urinary uric acid to urinary creatinine ratio and the result was statistically significant. $(p<0.001)$.

\section{Discussion}

WHO has defined perinatal asphyxia as "failure to initiate and sustain breathing at birth" $[6,7]$. The National Neonatal Perinatal Database (NNPD) used a similar definition for perinatal asphyxia. It defined moderate asphyxia as slow gasping breathing or an APGAR score of 4-6 at 1 minute of age. Severe asphyxia was defined as no breathing or an APGAR score of $0-3$ at 1 minute of age. APGAR scores are useful for predicting long-term outcome in infants with perinatal asphyxia [2]. 
Out of the total 45 newborns in the present study, 31 were females and 14 were males. 29 newborns had birthweight $<2.5 \mathrm{~kg}$ and 16 had birth weight $>$ $2.5 \mathrm{~kg}$.

The urinary uric acid levels of all newborns were measured, of which $8(17.8 \%)$ neonates had urinary uric acid levels in the range < 17.5, 22(48.9\%) neonates had urinary uric acid levels in the range of 17.5-18.5, and $15(33.3 \%)$ neonates had urinary uric acid levels were in range $>18.5$. The urinary creatinine levels measured in the same urine samples were all within the normal range.

In a study by Krishnan $\mathrm{E}$ et al, it was found that urinary uric acid to creatinine ratio was significantly higher in asphyxiated newborns than nonasphyxiated (0.78-4.94 vs $0.42-1.96)$. Similarly, in the present study, urinary uric acid to creatinine ratio was found to be $>1.96$ in $51.1 \%$ of asphyxiated neonates. Urinary uric acid to creatinine ratios was significantly higher in infants with severe HIE (3.18 \pm 0.61$)$ when compared with infants of moderate HIE (2.19 \pm 0.32$)$.

Amongst 28 neonates, who had $\mathrm{pH}$ in the range of 7.14-7.4, 22(78.6\%) neonates had urinary uric acid to creatinine ratio in the range of $0.42-1.96$, and $6(21.4 \%)$ neonates had ratio $>1.96$. Rest $17(37.8 \%)$ neonates who had $\mathrm{pH}<7.14$, had urinary uric acid to creatinine ratio $>1.96$. A study by Krishnan et al shows a negative correlation between the $\mathrm{pH}$ of cord blood of asphyxiated neonate to urinary uric acid to creatinine ratio which is following the findings in the present study [8].

In the study conducted by Krishnan $\mathrm{E}$ et al, there were significant differences of mean $\mathrm{UA} / \mathrm{Cr}$ ratio for APGAR score 4-6 vs APGAR score 0-3 ( $p<0.001$ ) where APGAR score at $1 \mathrm{~min}, 5 \mathrm{~min}$, and $10 \mathrm{~min}$ were found to be useful in the diagnosis of asphyxia and its severity. The present study shows a negative correlation between Urinary $\mathrm{UA} / \mathrm{Cr}$ ratio and APGAR score which is in agreement with the findings of Krishnan et al [8].

Pallab Basu et al conducted a randomized casecontrol study on 31 asphyxiated and 31 normal newborns to see whether urinary uric acid/ urinary creatinine can be used as a marker of perinatal asphyxia and can be correlated with the clinical diagnosis by APGAR score. It was observed that the urinary uric acid to creatinine ratios was significantly

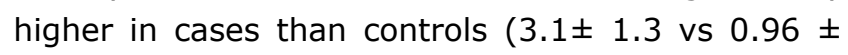
$0.54 ; \mathrm{P}<0.001$ ) and among asphyxia patients.
Also, a significant negative linear correlation was found between the uric acid to creatinine ratio and the APGAR score which was similar to the findings in the present study [9].

\section{Conclusion}

Urinary uric acid and creatinine ratio is a simple, cost-effective, and non-invasive laboratory test.

\section{What does the study add to the existing knowledge?}

It can be used as a supportive tool along with an APGAR score for assessing birth asphyxia.

\section{Author's contribution}

All the authors, Dr. Nikhil Gupta, Dr. Vedika A Bhat, Dr. Rashmi Katyal, Dr. Shikha Saxena, Dr. Shashank Mishra, contributed equally to the study.

\section{Reference}

01. Costello A, Francis V, Byrne A, Puddephatt C. State of the World's Newborns-A Report from Saving Newborn Lives. ERIC. 2001;12(5)1-4. [Crossref]

02. National Neonatal and Perinatal Database Report 2002-2003. 1-58.

Available at [Article] [Crossref]

03. Manzke $H$, Dörner $K$, Grünitz J. Urinary hypoxanthine, xanthine and uric acid excretion in new-born infants with perinatal complications. Acta Paediatric. 1977;66(6)713-717.

doi: 10.1111/j.1651-2227.1977.tb07977.x [Crossref]

04. Bhongir AV, Yakama AVV, Saha S, Radia SB, Pabbati J. The Urinary Uric Acid/Creatinine Ratio is An Adjuvant Marker for Perinatal Asphyxia. Europe J Pharmaceut Med Res. 2015;2(5)520528.

[Crossref]

05. Yashwanth K, Babu MS, Srinivas K, Mohan C, Aswani N, Rekha NA. A study of urinary uric acid to creatinine ratio in assessing the severity of birth asphyxia. IOSR J Dent Med Sci. $2017 ; 16(10) 69-76$.

[Crossref] 
06. World Health Organization. Working definitions neonatal and perinatal database South East Asia Regional. WHO, Geneva. 2006;1-7.

Available at [Article] [Crossref]

07. Nelson KB, Ellenberg JH. American Academy of Pediatrics- The APGAR scores. Advances in Neonatal Care. 2006;6(4)220-223.

[Crossref]
08. Krishnana E, Ponnusamy V, Sekar SP. Study of urinary uric acid and creatinine ratio as a marker of neonatal asphyxia for babies born in a tertiary care hospital. Int J Med Sci. 2017;5(12)5418-5423.

doi: $10.18203 / 2320-6012 . i j r m s 20175466$ [Crossref]

09. Basu P, Som S, Choudhury N, Das H. Correlation between APGAR score and urinary uric acid to creatinine ratio in perinatal asphyxia. Indian J Clin Biochem. 2008;23(4)361-364.

doi: $\quad 10.1007 / \mathrm{s} 12291-008-0079-2 \quad$ [Crossref] 